\title{
Demographic and Epidemiological Profile of Patients with Adult-onset Primary Open Angle Glaucoma in a Tertiary Niger-Delta Hospital, Nigeria
}

\author{
Onua, $\mathbf{A A}^{1}$, Pedro-Egbe $\mathrm{CN}^{2}$ \\ ${ }^{1}$ School of Public Health, University of Port Harcourt, Nigeria \\ ${ }^{2}$ Department of Ophthalmology, University of Port Harcourt, Nigeria \\ Corresponding Author: C.N. Pedro-Egbe
}

DOI: https://doi.org/10.52403/ijrr.20220218

\begin{abstract}
Background/Objective: This was a prospective study of patients attending the Glaucoma Clinic at University of Port Harcourt Teaching Hospital, Nigeria and were diagnosed with adult-onset Primary Open Angle Glaucoma (POAG). The objective of the study was to identify and report the demographic and epidemiological characteristics and comorbid states of patients diagnosed with adult-onset POAG.

Materials and Methods: Clinical assessment of patients combined with findings from clinical records and interviewer-administered semistructured questionnaire were used to obtain relevant data from the respondents between January and December 2021. Data collected included demographic data, ethnicity, comorbidity and family history of glaucoma.

Results: Eight hundred and fifty $(\mathrm{n}=850)$ POAG patients adult aged $\geq 40$ years were recruited in this study. The mean age was $60.5 \pm$ SD 10.1 years. The modal age group was 60-69 years. Seven hundred and seventy-two $(n=777 ; 90.8 \%)$ had various forms of visual impairment. Five hundred and twenty-six $(\mathrm{n}=526 ; 61.9 \%)$ had positive family history of glaucoma in first degree relatives while 120 (14.1\%) had positive family history of glaucoma in second degree relatives. Comorbidities associated with adultonset POAG were cataract (44\%), diabetes mellitus (30\%) and systemic hypertension (26\%).
\end{abstract}

Conclusion: Risk factors for adult-onset POAG in the Niger-Delta are similar to those reported in other black populations in Africa - impaired vision, positive family history of glaucoma, diabetes mellitus, systemic hypertension and cataract. Knowledge of patients' demographic and epidemiological details are vital for early detection and treatment, thereby reducing the scourge arising from POAG in our population.

Key Words: Adult-onset POAG, demographic profile, epidemiological profile, Niger-Delta Region, Nigeria

\section{INTRODUCTION}

Glaucoma is a group of optic neuropathies resulting from the gradual, progressive death of retinal ganglion cells with characteristic visual field changes associated with irreversible visual loss. Although raised intraocular pressure is one of the risk factors, its presence or absence does not have a role in its definition. Depending on how open the anterior chamber angle of the subject is at the time of clinical examination with gonio-lens, glaucoma can be classified either as "open angle" or "angle closure". In Primary OpenAngle Glaucoma, the aqueous drainage angles are sufficiently open for the egress of aqueous humor in the presence of characteristic optic neuropathy and visual field changes. Also, the age at onset of the disease may be used to classify glaucoma 
into congenital, infantile, juvenile or adult forms (Kanski., 2006).

Glaucoma is the leading cause of irreversible blindness worldwide affecting over70 million people in the world (Kapetanakis et al., 2016) (Bourne et al., 2016). Quigley et al estimated that over eleven million people will be bilaterally blind from primary glaucoma by 2020 (Quigley et al., 2006). Primary open-angle glaucoma accounts for $74 \%$ of all glaucoma cases and it is characterized by progressive loss of retinal ganglion cells (RGCs), damage to the optic nerve, and subsequent irreversible visual field loss2020 (Quigley et al., 2006). In Nigeria, primary open-angle glaucoma is the most prevalent variant; and the Niger Delta Region has the highest number of glaucoma patients in Nigeria being responsible for $20.8 \%$ of bilateral blindness (Pedro-Egbe et al., 2006).

Adult-onset primary open-angle glaucoma occurs from the age of 40 years (Allen et al., 2015) (Fan et al., 2010)(Kyari et al., 2015) (Awoyesuku et al., 2012). Early-onset POAG (before age 40) exhibits Mendelian inheritance, while the adult-onset form is often inherited as complex traits and multifactorial, progressing slowly and relentlessly with elevated IOP that is too high for the healthy eye (Allen et al., 2015) (Fingert (2011).

The etiopathogenesis of adult-onset POAG is not entirely clear. Epidemiologic studies suggest various risk factors, including age, positive family history, race, genetic factors, elevated intraocular pressure (IOP), thin central corneal thickness (CCT), low ocular perfusion pressure (OPP), vascular factors, systemic disease, diabetes mellitus, myopia, and cigarette smoking (Grant et al., 1982) as playing a role in the pathogenesis.

\section{MATERIALS AND METHODS}

This was a prospective study of adult-onset primary open-angle glaucoma (POAG) patients attending the Glaucoma Clinic of the Department of Ophthalmology at University of Port Harcourt Teaching
Hospital, Nigeria; The study was carried out between January and December 2021. Measurement of the distant and near visions of study subjects was carried out at a distance of 6 meters with the aid of illuminated Snellen's chart; pinhole was presented when VA was less than 6/9. Near vision was assessed at $40 \mathrm{~cm}$. Basic ocular examinations (which included checking the eyelids for trichiasis, globe for phthisis, cornea for opacity or pterygium, pupil for pupillary light reaction) were done with the aid of a pen touch. The anterior chamber depth, state of the lens, vitreous, retina and optic nerve were assessed using Topview Optics'slitlamp-LS-4. Fundoscopy was carried out with +78D lens. Pupillary dilatation was achieved using Mydriacyl $0.5 \%$ after refraction and measurement of the intraocular pressure. Objective refraction was done with streak retinoscope and then subjectively refined. Intraocular pressure measurement was done using Perkin's applanation tonometer (MK2model), after instilling local anaesthetic agent (1\% tetracaine) and fluorescein dye into the conjunctival sac. IOPs was measured in both eyes three consecutive times. The measurements were done with the subjects in sitting position. The mean IOP value was adopted. All the measurements were carried out by the leadauthor to avoid inter-observers' error.

Presbyopic corrections- glasses (readers) were given to deserving subjects while those requiring further management and surgery were referred to the appropriate sub-specialties in the department. Relevant findings from clinical records to elicit comorbid status and an interviewer administered semi-structured questionnaire were used to obtain relevant data from the respondents. The data obtained were entered into Microsoft Excel sheet and later exported to IBM Statistical Package for Social Sciences version 25 software (SPSS) Inc; Chicago, IL, USA for statistical analysis. Relevant data were presented in tables and charts. Statistical significance 
Onua, AA et.al. Demographic and epidemiological profile of patients with adult-onset primary open angle glaucoma in a tertiary Niger-Delta Hospital, Nigeria.

was performed using Chi square and statistical significance was set at $p \leq 0.05$.

\section{RESULTS}

Table 1: Age distribution of the study population

\begin{tabular}{|l|c|l|l|l|}
\hline $\begin{array}{l}\text { Total Participants } \\
\text { N= 850 }\end{array}$ & $\mathbf{n}$ & $\mathbf{\%}$ & $\begin{array}{l}\text { Chi Square } \\
\text { value }\end{array}$ & $\begin{array}{l}\text { p- } \\
\text { value }\end{array}$ \\
\hline Age Group & & & 0.042 & 1.000 \\
\hline $40-49$ & 130 & 15.3 & & \\
\hline $50-59$ & 240 & 28.2 & & \\
\hline $60-69$ & 364 & 42.8 & & \\
\hline $70-79$ & 72 & 8.5 & & \\
\hline 80 and older & 44 & 5.2 & & \\
\hline $\begin{array}{l}\text { Mean Age 60.5 10.1 years } \\
\text { Age Range-40 to 88 years }\end{array}$ \\
\hline
\end{tabular}

The age distribution of the study population is presented in table 1. Eight hundred and fifty adult-onset POAG patients $(\geq 40$ years) were seen during the study period representing $62.6 \%$ of the total number of glaucoma patients seen during the same period.

The mean age of study participants was $60.5 \pm$ SD 10.1 years; with a range of
40-88 years and a modal of 60-69 years. The differences in the age of participants was however, not statistically significant $(\mathrm{p}=1.000)$ [table 1].

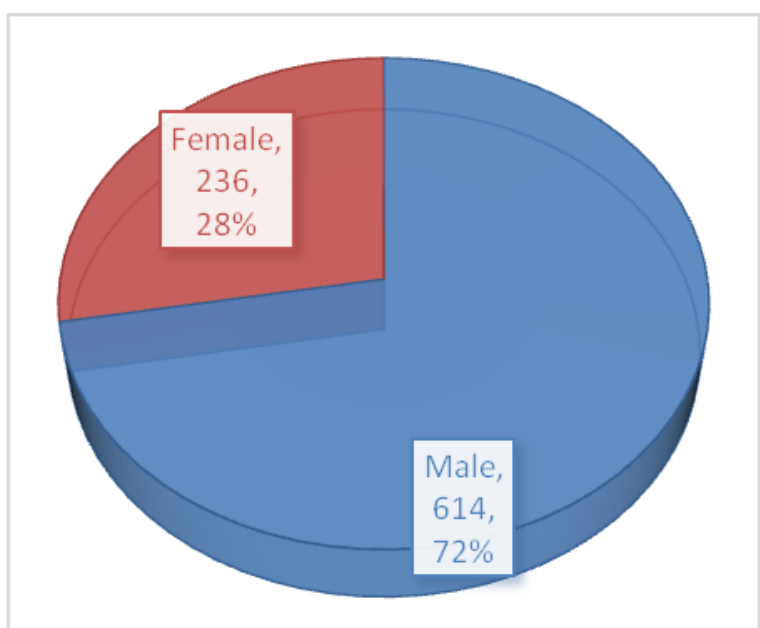

Figure 1: Gender distribution in the study population

Figure 1 depicts the gender distribution in the study population The male to female ratio was $2.6: 1$.

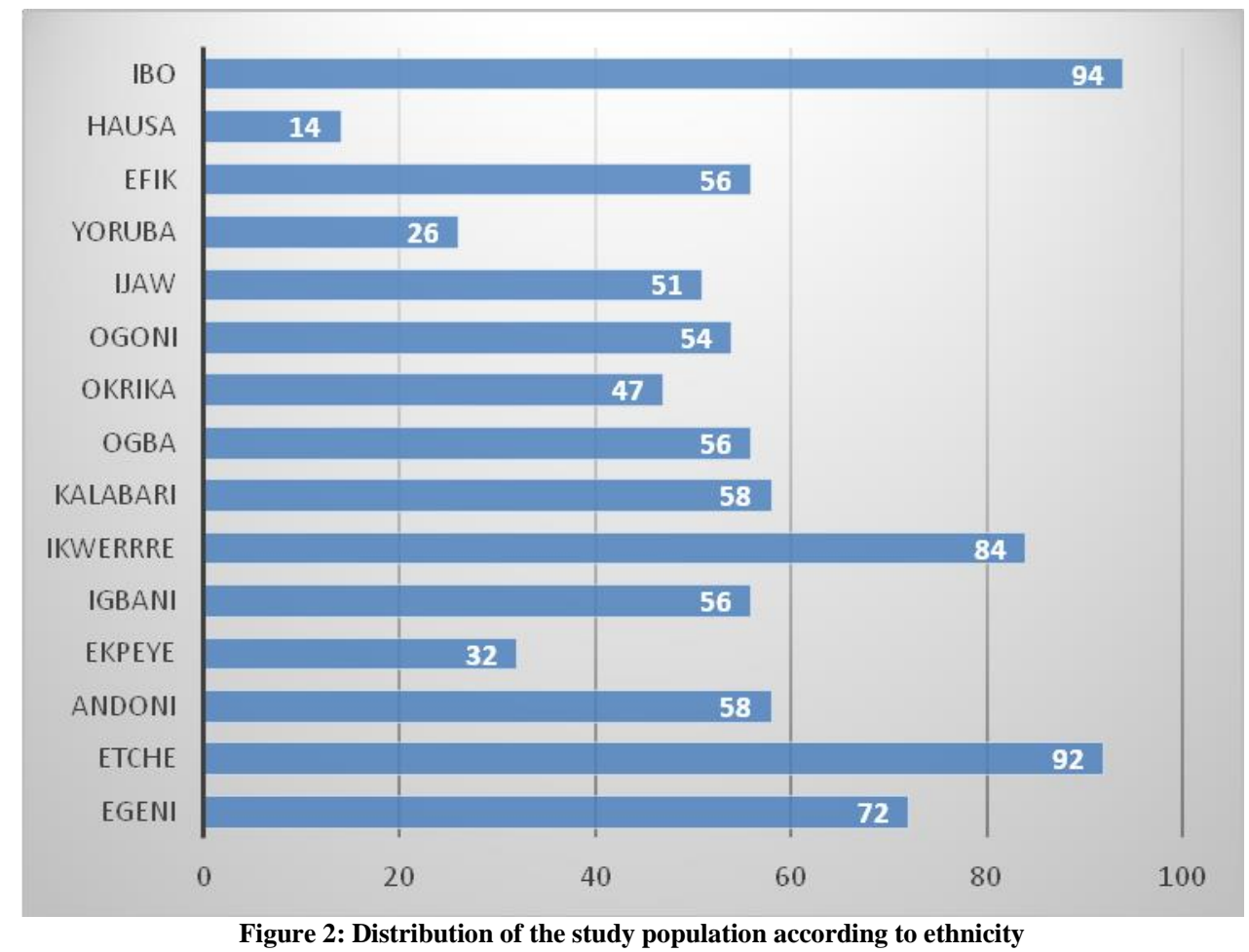

The study population were from different ethnic groups across Nigeria as shown in figure 2:

Ibo $(11.1 \%)$, Etche $(10.8 \%)$, Ikwerre (9.9\%), Engenni (8.4\%), Andoni (6.8\%),
Kalabari (6.8\%), Igbani (6.6\%), Ogba (6.6\%), Efik (6.6\%), Ogoni (6.4\%, Ijaw (6.0\%), Okrika (5.5\%), Ekpeye (3.8\%), Yoruba (3.1\%) and Hausa (1.6\%). 
Onua, AA et.al. Demographic and epidemiological profile of patients with adult-onset primary open angle glaucoma in a tertiary Niger-Delta Hospital, Nigeria.

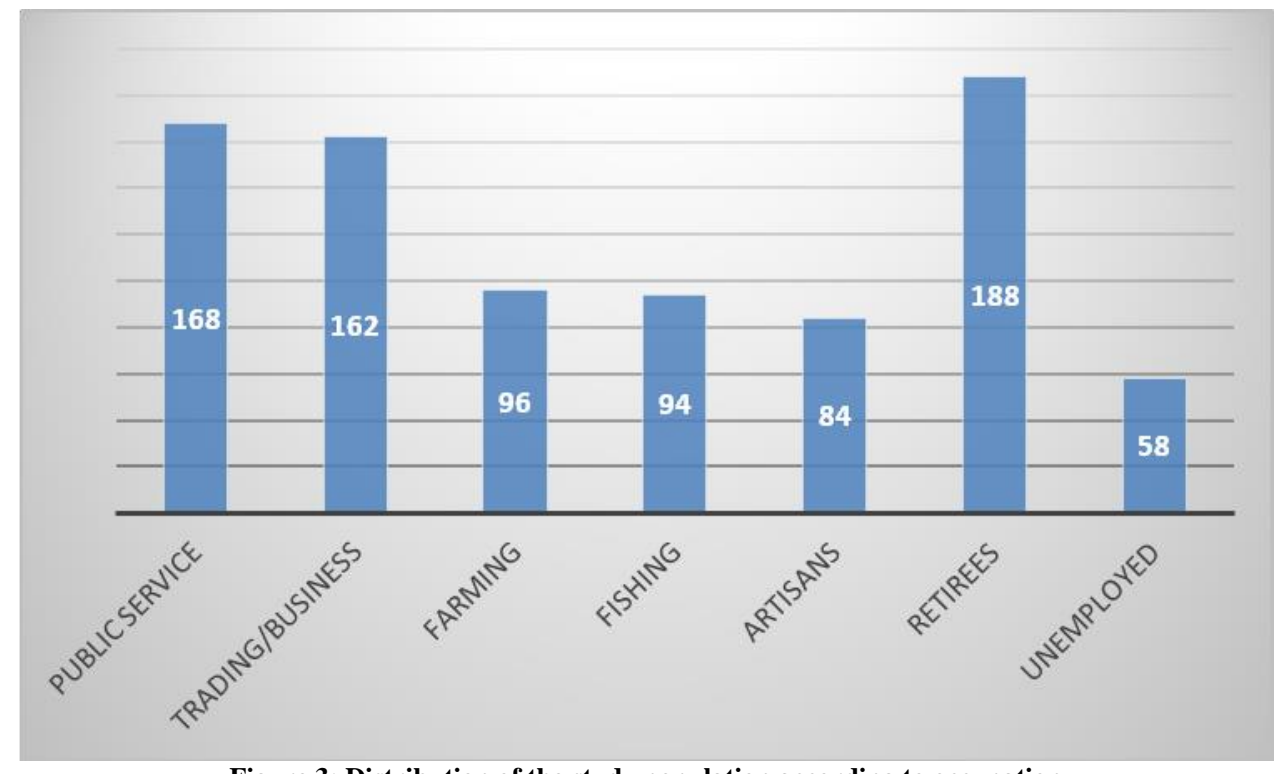

Figure 3: Distribution of the study population according to occupation

Majority of the study participants were retirees from public service representing $22.1 \%$ while the unemployed accounted for $6.8 \%$ of the study population. Over $19 \%$ of the study participants are in active public service, $11.3 \%$ engaged in farming, $11.1 \%$ in fishing, $19 \%$ in trading/business and $9.9 \%$ are artisans [figure 3].

Table 2: Ocular characteristics of study subjects

\begin{tabular}{|c|c|c|c|c|}
\hline Variable & $\begin{array}{c}\text { Distribution i } \\
(\mathbf{N})\end{array}$ & $\begin{array}{l}\text { set POAG cases } \\
(\%)\end{array}$ & Chi Square & p-value \\
\hline $\begin{array}{l}\text { Best Presenting Visual Acuity } \\
\text { No Visual Impairment } \\
\text { Moderate Visual Impairment } \\
\text { Severe Visual Impairment } \\
\text { Blind } \\
\text { TOTAL }\end{array}$ & $\begin{array}{l}78 \\
216 \\
504 \\
52 \\
850\end{array}$ & $\begin{array}{c}(9.2) \\
(25.4) \\
(59.3) \\
(6.1) \\
(100)\end{array}$ & 324.225 & 0.000 \\
\hline $\begin{array}{l}\text { Best Corrected Visual Acuity } \\
\text { No Visual Impairment } \\
\text { Moderate Visual Impairment } \\
\text { Severe Visual Impairment } \\
\text { Blind } \\
\text { TOTAL }\end{array}$ & $\begin{array}{l}225 \\
260 \\
340 \\
25 \\
850\end{array}$ & $\begin{array}{c}(26.5) \\
(30.6) \\
(40.0) \\
(2.9) \\
(100)\end{array}$ & 76.090 & 0.000 \\
\hline $\begin{array}{l}\text { Positive Family History of Glaucoma } \\
\text { First Degree Relative } \\
\text { Second Degree Relative } \\
\text { Unaware } \\
\text { TOTAL }\end{array}$ & $\begin{array}{c}526 \\
120 \\
204 \\
850\end{array}$ & $\begin{array}{l}(61.9) \\
(14.1) \\
(24.0) \\
(100)\end{array}$ & 573.994 & 0.000 \\
\hline
\end{tabular}

The ocular characteristics of the study population is presented in table 2 . Seven hundred and seventy-two $(n=772$; $90.8 \%$ ) had various forms of visual impairment (visual acuity $<6 / 18$ in the better eye) at the time of presentation; moderate visual impairment (VA less than6/18 to $6 / 60$ in the better eye) accounted for $25.4 \%$, while severe visual impairment (VAless than $6 / 60$ to $3 / 60$ (WHO, 2011). Fifty-two $(\mathrm{n}=52 ; 6.1 \%)$ persons were blind (VAless than $3 / 60$ to no perception of light). The difference in the presenting visual acuity of study participants was statistically significant $(\mathrm{p}=0.000)$ [table 2]. However, there was a statistically significant difference in the best corrected visual acuity. Two hundred and twenty-five subjects representing $26.5 \%$ had no visual impairment; $30.6 \%$ had moderate visual impairment and $40 \%$ had severe visual impairment while $2.9 \%$ were blind[table 2].

Five hundred and twenty-six $(\mathrm{n}=526$; $61.9 \%$ ) of the study population had a 
positive family history of glaucoma in first degree relatives while $120(14.1 \%)$ had positive family history of glaucoma in second degree relatives and $24 \%$ were unaware of any history of glaucoma among family members [table 2].

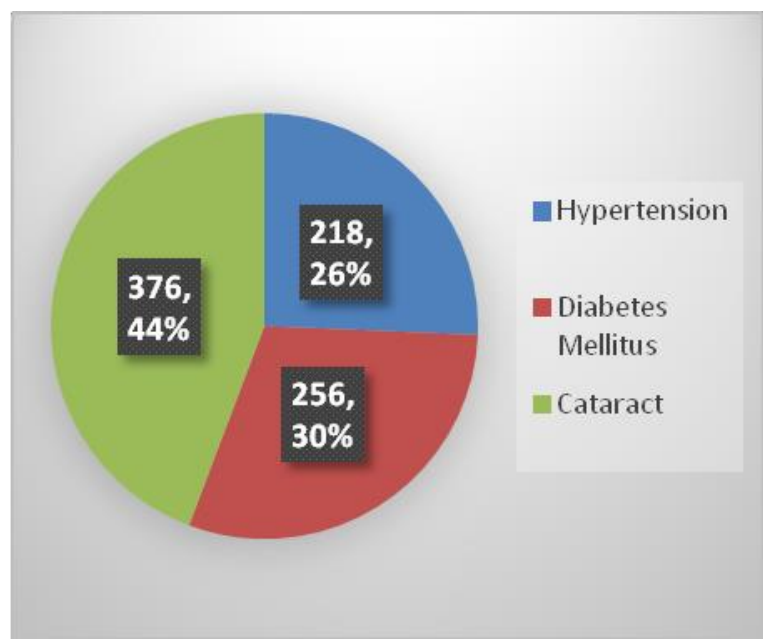

Figure 4-Showing major comorbidities associated with adultonset POAG in the study population

The major comorbidities associated with adult-onset POAG in the study population were cataract $(44 \%)$, diabetes mellitus $(30 \%)$ and systemic hypertension $(26 \%)$.

\section{DISCUSSION}

Adult-onset primary open-angle glaucoma is the most frequent form of POAG and a major cause of optic nerve degeneration with subsequent progressive, irreversible vision loss (Bourne et al., 2016). Individuals of African descent are disproportionately more affected by POAG with greater severity, more rapid progression and more often leading to blindness and decrease in quality of life (Mafwiri et al., 2005)(Ntim-Amponsah, 2002)(Quigley et al., 1996)(Broman et al., 2008) (Quigley et al., 1994).

The etiopathogenesis of adult-onset POAG is still not very clear, thereby hindering attempts at early identification and treatment of this disease. Currently, elevated intraocular pressure (IOP) remains the only treatable and modifiable risk factor of this disease, although high IOP is neither necessary nor sufficient to develop glaucoma (Sommer et al., 1991). In order to improve on the prevention and treatment, it is important to understand the prevalent local epidemiological peculiarities and demographical characteristics associated with adult-onset POAG. The focus of this work therefore, is to provide a comprehensive analysis of the local epidemiological determinants and the comorbidities associated with adult-onset POAG in the Niger-Delta region of Nigeria and proffer epidemiologically based solutions to improve early detection of cases and treatment of POAG.

This work studied 850adult-onset POAG patients $(\geq 40$ years $)$ representing $62.6 \%$ of the total number of glaucoma patients seen during the same period. The age range of our study population was 40 to 88 years, mean age of $60.5 \pm$ SD 10.1 years and modal group was $60-69$ years(table 1$)$. The gender distribution in the study population was in favor of the males with a male to female ratio was 2.6:1. This observation compares well with the study of Kyari et al. in the Nigeria National Blindness and Visual Impairment Survey of 2005-2007. In their nationally representative sample of 13,591 people aged $\geq 40$ years, the mean age of subjects with POAG was66.2 \pm 12.3 years. Working independently and in different periods of time, Murdoch et al in a study among 1563 people of Hausa/Fulani ethnic extraction, Nigeria; reported that POAG was more prevalent among individuals aged 45 years (Murdoch et al., 2001) and Adeoye in South Western region of Nigeria also observed that POAG was more prevalent among individuals aged 50 years and older accounting for $11.1 \%$ of blindness (Adeoye, 2001). Collaborating these findings, Leske et al in the Barbados Eye Study noted that the risk of POAG significantly increases with age in all populations. Murdoch et al postulated that older black populations may exhibit a tendency to present with more advanced disease at diagnosis, including severe optic nerve cupping and extensive visual field loss (Nouri-Mahdavi et al., 2004). 
Different ethnic groups in Nigeria were represented in our study depicting the metropolitan nature of Port Harcourt, the Oil hub and center for Oil and Gas-related industrial and commercial activities. The study population were from Ibo (11.1\%), Etche (10.8\%), Ikwerre (9.9\%), Engenni (8.4\%), Andoni (6.8\%), Kalabari (6.8\%), Igbani (6.6\%), Ogba (6.6\%), Efik (6.6\%), Ogoni (6.4\%, Ijaw (6.0\%), Okrika (5.5\%), Ekpeye $(3.8 \%)$, Yoruba $(3.1 \%)$ and Hausa (1.6\%) [figure 1]. Ibo accounted for the highest proportion of those diagnosed with adult-onset POAG in this study. A similar observation was noted in the Nigerian National Low Vision and Blindness Survey where the Igbo ethnic group had $73 \%$ higher odds of POAG than the Hausa and the highest prevalence of POAG among Nigerians (OR 1.73, $95 \%$ CI 1.18-2.56; $\mathrm{p}=$ 0.01) (Kyari et al., 2015). Different authors have also reported a notably higher prevalence of glaucoma among Africans (Friedman et al., 2006) (Lichter et al., 2001) (Kyari et al., 2015). In this study, 772 (90.8\%) of the study participants had various forms of visual impairment at the time of presentation: Moderate visual impairment accounted for $25.4 \%$; severe visual impairment $(59.3 \%)$ while $6.1 \%$ were blind. The difference in the presenting visual acuity of the study participants was statistically significant $(\mathrm{p}=0.000)$ [table 2]. However, there was a statistically significant difference in the best corrected visual acuity.

A family history of glaucoma increases the risk of an individual developing the disease. Although the exact inheritance pattern is still unknown, adultonset POAG is a multifactorial polygenetic disease. In this study,61.9\% subjects had a positive family history of glaucoma in first degree relatives and $14.1 \%$ in second degree relative; $24 \%$ were unaware of any history of glaucoma among family members. Our result collaborates the findings of the Barbados Family Study of Open-angle Glaucoma, Glaucoma Inheritance Study in Tasmania and the Rotterdam Eye Study which found that a family history of glaucoma was a risk factor for developing POAG. The Glaucoma Inheritance Study compared the distribution of patients with genealogically confirmed familial POAG and those with sporadic POAG (Wu et al., 2006). The Rotterdam Study, ascertained family history by direct examination of relatives and not by patient self-report (Wolfs et al.,1998). The Barbados Family Study investigated inheritance of POAG among families of black race and also found family history to be a major risk factor for glaucoma confirmed by direct examination of the relatives (Leske et al., 2001). In the Rotterdam Study, the lifetime absolute risk of glaucoma at age 80 years was found to be almost 10 times higher for individuals with positive family history of glaucoma than patients with a negative family history (22.0\% vs. $2.4 \%$ )(Wolfs et al.,1998).

The major comorbidities associated with adult-onset POAG in our study population were cataract, diabetes mellitus and systemic hypertension. Our findings agree with other studies in other centers (Klein et al., 1994)(Leske et al., 2003).In the Beaver Dam Eye Study, Klein et al noted that the prevalence of POAG was higher in diabetic individuals compared to none diabetics $(4.2 \%$ versus $2.0 \% ; \mathrm{P}=0.004)$ and in the Baltimore Eye Survey, persons whose POAG had been diagnosed before they enrolled in the study showed a positive association with diabetes (odds ratio, 1.7, $95 \%$ confidence interval, $1.03,2.86$ ).In the Blue Mountains Eye Study participants with glaucoma were more likely to have systemic hypertension than participants without glaucoma $(65.7 \% \quad(95 \% \quad$ CI: $56.6-74.8)$ versus $45.4 \%$ (95\% CI: 43.8-47.1) (Lee et al., 2006)(Leighton et al. 1972).In our study, $26 \%$ of our study participants had systemic hypertension.

Cataract and POAG are common comorbidities, as the conditions are prevalent in the aging population. However, a definitive correlation between these comorbidities has not been established. The Barbados Eye Study found that cataracts 
Onua, AA et.al. Demographic and epidemiological profile of patients with adult-onset primary open angle glaucoma in a tertiary Niger-Delta Hospital, Nigeria.

were more common among POAG cases than controls (Leske et al.,1995). In our study, $44 \%$ of our respondents had coexisting unilateral or bilateral cataract.

\section{CONCLUSION}

Risk factors for adult-onset POAG in the Niger-Delta are similar to those reported in other black populations in Africa. Patients with adult-onset POAG are associated with impaired vision, positive family history of glaucoma, cataract, diabetes mellitus and systemic hypertension. A knowledge of patients' demographic and epidemiological details are vital for early detection and treatment of the disease; thereby reducing the likely scourge that would result from POAG in the population. This finding is in support of the value of tailored screening particularly of family members of individuals with a positive family history of glaucoma.

Financial Support and Sponsorship: This work had financial support from Tertiary Education Trust Fund (TET Fund) Institution-Based Research Grant of the University of Port Harcourt, Nigeria.

Conflicts of Interest: There are no conflicts of interest

\section{Acknowledgement: None}

\section{Ethical Approval: Approved}

\section{REFERENCES}

1. Adeoye, A. (1996). "Survey of blindness in rural communities of South-western Nigeria," Tropical Medicine and International Health; 1(5): 672-676.

2. Awoyesuku, E.A. \& Pedro-Egbe, C.N. (2012). Clinical forms of glaucoma in a tertiary hospital in NigeriaPH Med. $J$; 6 : 333-338.

3. Bourne, R.R., Taylor, H.R., Flaxman, S.R. et al., (2016). Number of people blind or visually impaired by glaucoma worldwide and in world regions 1990 - 2010: a metaanalysis. PLoS One; 11: e0162229.
4. Broman, A.T., Quigley, H.A., West, S.K., Katz, J., Munoz, B., (2008). Estimating the rate of progressive visual field damage in those with open-angle glaucoma, from cross-sectional data. Invest Ophthalmol Vis Sci; 49:66-76. [PubMed: 18172076].

5. Fingert, J.H. (2011). Primary Open-Angle Glaucoma Genes. Eye; 25: 587-595.

6. Friedman, D.S., Jampel, H.D., Munoz, B., West, S.K., (2006). The Prevalence of Open-angle Glaucoma Among Blacks and Whites 73 Years and Older: The Salisbury Eye Evaluation Glaucoma Study. Arch Ophthalmol; 124:1625-1630.

7. Grant, W.M., Burke, J.F. Jr.,(1982). Why do some people go blind from glaucoma? Ophthalmology; 89:991-998.

8. Kapetanakis. V.V., Chan, M.P., Foster, P.J.(2006). Global variations and time trends in the prevalence of primary open angle glaucoma (POAG): a systematic review and meta-analysis. Br J Ophthalmol; 100: 86-93.

9. Klein, B.E., Klein, R., Jensen, S.C. (1994). Open-angle glaucoma and older-onset diabetes. The Beaver Dam Eye Study. Ophthalmology; 101:1173-1177.

10. Kyari F, Abdull MM, Wormald R, Evans JR, Nolan W, Murthy GV, Gilbert CE; Nigeria National Blindness and Visual Impairment Study Group. Risk factors for open-angle glaucoma in Nigeria: results from the Nigeria National Blindness and Visual Impairment Survey. BMC Ophthalmol. 2016 Jun 7;16:78. doi: 10.1186/s12886-016-0264-7. PMID: 27267038; PMCID: PMC4895902.

11. Lee, A.J., Wang, J.J., Kifley, A., Mitchell, P. (2006). Open-angle glaucoma and cardiovascular mortality: the Blue Mountains Eye Study. Ophthalmology; 113:1069-1076.

12. Leighton, D.A., Phillips, C.I. (1972). Systemic blood pressure in open-angle glaucoma, low tension glaucoma, and the normal eye. Br J Ophthalmol;56:447-453.

13. Leske, M.C., Connell, A.M., Wu, S.Y., Hyman, L.G., Schachat, A.P. (1995). Risk factors for open-angle glaucoma. The Barbados Eye Study. Arch Ophthalmol; 113:918-924. [PubMed: 7605285]

14. Leske, M.C., Heijl, A., Hussein, M., Bengtsson, B., Hyman, L., Komaroff, E. (2003). Factors for glaucoma progression and the effect of treatment: the early 
Onua, AA et.al. Demographic and epidemiological profile of patients with adult-onset primary open angle glaucoma in a tertiary Niger-Delta Hospital, Nigeria.

manifest glaucoma trial. Arch Ophthalmol; 121:48-56

15. Leske, M.C., Nemesure, B., He, Q., Wu, S.Y., Fielding, H.J., Hennis,A. (2001). Patterns of open-angle glaucoma in the Barbados Family Study. Ophthalmology; 108:1015-1022.

16. Leske, M.C., Wu, S.Y., Hennis, A., Honkanen, R., Nemesure, B., BESs Study Group. (2008). Risk factors for incident open-angle glaucoma: the Barbados Eye Studies. Ophthalmology; 115:85-93. [PubMed: 17629563].

17. Lichter, P.R., Musch, D.C., Gillespie, B.W. (2001). Interim clinical outcomes in the Collaborative Initial Glaucoma Treatment Study comparing initial treatment randomized to medications or surgery. Ophthalmology; 108:1943-1953.

18. Mafwiri, M., Bowman, R.J., Wood, M., Kabiru, J. (2005). Primary open-angle glaucoma presentation at a tertiary unit in Africa: intraocular pressure levels and visual status. Ophthalmic Epidemiol; 12:299-302. [PubMed: 16272049]

19. Murdoch, I.E., Cousens,S.N., Babalola, O.E. (2001). "Glaucoma prevalence may not be uniformly high in all "black" populations," African Journal of Medicine \& Medical Sciences; 30 (4): 337-339.

20. Ntim-Amponsah, C.T. (2002). Visual loss in urban and rural chronic glaucoma patients in Ghana. Trop Doct.; 32:102-104. [PubMed: 11931187].

21. Nouri-Mahdavi,K., Hoffman, D., Coleman, A.L., Liu, G., Li, G. (2004). Predictive factors for glaucomatous visual field progression in the Advanced Glaucoma Intervention Study. Ophthalmology; 111:1627-1635. [PubMed: 15350314].

22. Pedro-Egbe, C.N., Chukwuka, I.O., Babatunde, S., Umeh, R.E. (2006). Blindness and Visual Impairment in the Niger-Delta: A study of Ahoada-East Local Government Area of Rivers State, Nigeria. PH Med. J; 1(1), 56-61.
23. Quigley, H.A., Tielsch, J.M., Katz, J., Sommer, A.(1996). Rate of progression in open-angle glaucoma estimated from crosssectional prevalence of visual field damage. Am J Ophthalmol; 122:355-363. [PubMed: 8794708]

24. Quigley, H.A., Broman, A.T. (2006). The number of people with glaucoma worldwide in 2010 and 2020. Br J Ophthalmol; 90: 262-267.

25. Quigley, H.A., Enger, C., Katz, J., Sommer, A., Scott, R. (1994). Risk factors for the development of glaucomatous visual field loss in ocular hypertension. Arch Ophthalmol; 112:644-649. [PubMed: 8185522]

26. Sommer,A., Tielsch, J.M., Katz, J., Quigley, H.A., Gottsch, J.D. (1991). Relationship between intraocular pressure and primary open angle glaucoma among white and black Americans. The Baltimore Eye Survey. Arch Ophthalmol; 109:1090-1095. [PubMed: 1867550]

27. World Health Organization (2011). Magnitude and cause of visual impairment. WHO Fact Sheet No. 282. Geneva: WHO. Available from: $<$ http://www.who.int/mediacentre/factsheets /fs282/en/> [accessed 10/12/ 2021].

28. Wolfs, R.C., Klaver, C.C., Ramrattan, R.S., van Duijn, C.M., Hofman, A., de Jong, P.T. (1998) Genetic risk of primary open-angle glaucoma. Population-based familial aggregation study. Arch Ophthalmol; 116: 1640-5.

29. Wu, J., Hewitt, A.W., Green, C.M. (2006). Disease severity of familial glaucoma compared with sporadic glaucoma. Arch Ophthalmol; 124:950-954.

How to cite this article: Onua, AA, Pedro-Egbe $\mathrm{CN}$. Demographic and epidemiological profile of patients with adult-onset primary open angle glaucoma in a tertiary Niger-Delta Hospital, Nigeria. International Journal of Research and Review. 2022; 9(2): 123-130. DOI: https://doi. org/10.52403/ijrr.20220218 